\title{
Caffeine attenuates scopolamine-induced memory impairment in humans
}

Citation for published version (APA):

Riedel, W., Hogervorst, E., Leboux, R., Verhey, F., \& Jolles, J. (1995). Caffeine attenuates scopolamineinduced memory impairment in humans. Psychopharmacology, 122(2), 158-168.

https://doi.org/10.1007/BF02246090

Document status and date:

Published: 01/01/1995

DOI:

10.1007/BF02246090

Document Version:

Publisher's PDF, also known as Version of record

Document license:

Taverne

Please check the document version of this publication:

- A submitted manuscript is the version of the article upon submission and before peer-review. There can be important differences between the submitted version and the official published version of record.

People interested in the research are advised to contact the author for the final version of the publication, or visit the DOI to the publisher's website.

- The final author version and the galley proof are versions of the publication after peer review.

- The final published version features the final layout of the paper including the volume, issue and page numbers.

Link to publication

\footnotetext{
General rights rights.

- You may freely distribute the URL identifying the publication in the public portal. please follow below link for the End User Agreement:

www.umlib.nl/taverne-license

Take down policy

If you believe that this document breaches copyright please contact us at:

repository@maastrichtuniversity.nl

providing details and we will investigate your claim.
}

Copyright and moral rights for the publications made accessible in the public portal are retained by the authors and/or other copyright owners and it is a condition of accessing publications that users recognise and abide by the legal requirements associated with these

- Users may download and print one copy of any publication from the public portal for the purpose of private study or research.

- You may not further distribute the material or use it for any profit-making activity or commercial gain

If the publication is distributed under the terms of Article $25 \mathrm{fa}$ of the Dutch Copyright Act, indicated by the "Taverne" license above, 


\begin{abstract}
Caffeine consumption can be beneficial for cognitive functioning. Although caffeine is widely recognized as a mild CNS stimulant drug, the most important consequence of its adenosine antagonism is cholinergic stimulation, which might lead to improvement of higher cognitive functions, particularly memory. In this study, the scopolamine model of amnesia was used to test the cholinergic effects of caffeine, administered as three cups of coffee. Subjects were 16 healthy volunteers who received $250 \mathrm{mg}$ caffeine and $2 \mathrm{mg}$ nicotine separately, in a placebo-controlled double-blind cross-over design. Compared to placebo, nicotine attenuated the scopolamine-induced impairment of storage in short-term memory and attenuated the scopolamine-induced slowing of speed of shortterm memory scanning. Nicotine also attenuated the scopolamine-induced slowing of reaction time in a response competition task. Caffeine attenuated the scopolamine-induced impairment of free recall from short- and long-term memory, quality and speed of retrieval from long-term memory in a word learning task, and other cognitive and non-cognitive measures, such as perceptual sensitivity in visual search, reading speed, and rate of finger-tapping. On the basis of these results it was concluded that caffeine possesses cholinergic cognition enhancing properties. Caffeine could be used as a control drug in studies using the scopolamine paradigm and possibly also in other experimental studies of cognitive enhancers, as the effects of a newly developed cognition enhancing drug should at least be superior to the effects of three cups of coffee.
\end{abstract}

Key words Caffeine Nicotine Scopolamine Cognition · Aging $\cdot$ Alzheimer's disease

W. Reidel $(\bowtie) \cdot$ E. Hogervorst $\cdot$ R.Leboux $\cdot$ F. Verhey H. van Praag $\cdot$ J. Jolles

Department of Psychiatry and Neurophysiology, University of Limburg, PO Box 616, NL-6200 MD Maastricht, The Netherlands

\section{Introduction}

In recent years, much effort has been put into the development of cognition enhancing drugs to combat syndromes seen in the age-associated cognitive decline and in dementia (Cacabelos et al. 1994). This has probably also stimulated interest in the cognitive effects of caffeine and nicotine. These substances have long since penetrated the consumer markets and, possibly as a result of this, knowledge about their acute and longterm effects on cognitive performance in humans by far exceeds what is known about any novel, putative cognitive enhancer.

The effects of nicotine on cognitive functions have been extensively studied in healthy persons, smokers, non-smokers, subjects with scopolamine-induced cholinergic blockade, and in patients with Alzheimer's disease (AD) (Rusted and Eaton-Williams 1991; Jones et al. 1992; Wesnes and Parrott 1992). The mechanism by which nicotine exerts its effects on cognition is by agonism of nicotinic acetylcholine receptors. Nicotine might play a role in the prevention of $\mathrm{AD}$ by maintaining cholinergic function better in old age (Levin 1992).

Improved performance on psychological tasks has also been reported frequently after caffeine intake in normal subjects, even with dosages as low as $32 \mathrm{mg}$ (Lieberman et al. 1987), in well-controlled double-blind studies, whereas only a few studies report detrimental effects on psychological task performance (Nehlig et al. 1992; Stavric 1992). The observed effects are described in terms of increased vigilance, arousal, activation, alertness, psychomotor speed, and mood. Learning and memory were improved by caffeine in one study (Loke 1988) but impaired in another (Terry and Phifer 1986). An interesting study describing a positive effect of caffeine on cognitive function, including memory, involved 7414 people distributed over age groups of about 20,30,40,50, and 60 years (Jarvis 1993). A positive linear relationship existed between 
the daily coffee consumption and cognitive performance. Older people appeared to be more susceptible to the performance-improving effects of caffeine than were younger people.

Adenosine antagonism is assumed to be the most important mechanism for explaining the stimulating effects of caffeine on behaviour (Nehlig et al. 1992; Stavric 1992). Potential cognition enhancers include adenosine $\mathrm{A}_{\mathrm{H}}$-antagonists since inhibitory adenosine $\mathrm{A}_{1}$-receptors have been found on cholinergic terminals in the hippocampus and the cortex (Briley 1990). If this mechanism is involved in caffeine's mode of action, then the cognition enhancing rather than merely the activating properties of caffeine would underlie the beneficial effect of caffeine on learning and memory performance.

In this study we investigated whether caffeine consumption improves memory performance. Despite its known limitations, the scopolamine model of cholinergic dysfunction is a recognized screening paradigm to assess the memory and cognition enhancing properties of substances proposed to combat the age-associated decline in cognitive performance or dementia of the Alzheimer type (Bartus et al. 1985; Rusted and Warburton 1988; Wesnes et al. 1988; Molchan et al. 1992). We used the scopolamine model to induce cognitive deficits in healthy volunteers. Despite the vast amount of literature describing the psychological effects of caffeine, such a study has, to the best of our knowledge, never been carried out until now. We postulated that the consumption of coffee would reverse or attenuate the impairing effects of scopolamine, particularly upon memory performance, as compared to the effect of decaffeinated coffee. We also compared the effects of caffeine with the known effects of nicotine upon scopolamine-induced cognitive dysfunction (Rusted and Eaton-Williams 1991), and for this reason double-blind administration of chewing gum with or without nicotine was included as an "active drug control".

\section{Material and methods}

\section{Subjects}

Eighteen healthy volunteers, balanced for sex, between 25 and 35 years of age were recruited. During the study, two subjects dropped out, one for reasons unrelated to the study, and the other because of adverse effects of scopolamine. These consisted of blurred vision and problems with balance. The scopolamine dose was weight calibrated $0.5 \mathrm{mg} / 75 \mathrm{~kg}$, and as this subject weighed $90 \mathrm{~kg}$ the actual dose was $0.6 \mathrm{mg}$. Since no other subjects over $75 \mathrm{~kg}$ had started the study, it was decided to maintain the dose regimen, except that $0.5 \mathrm{mg}$ would be the maximum dose. All subjects agreed to refrain from taking any form of medication, except oral contraceptives, during the study. All were moderate smokers (1-10 cigarettes/day) and had normal binocular acuity. The female volunteers were ascertained not to be pregnant. Exclusion criteria included any cardiac, hepatic, renal, pulmonary, neurological, gastrointestinal, haematological, or psychiatric conditions, as determined from the history, physical examination, ECG, and routine laboratory blood screens, a body weight $10 \%$ outside of population norms, a history of alcohol or drug abuse, excessive drinking ( $>28$ units/week; 1 unit $=12.5$ $\mathrm{ml}$ pure ethanol), caffeine intolerance, rare or extreme use of caffeine (i.e. $<7$ cups per week or $>10$ cups each day), glaucoma, allergic reactions to cholinergic drugs, and sensory or motor impairments which could reasonably be expected to affect psychomotor performance.

The study was approved by the standing Medical Ethics Review Committee of the University and written informed consent was given by all subjects. The subjects were paid for their participation.

\section{Study design}

The study was conducted according to a $3 \times 3$ repeated measurements model (Fig. 1). The first factor, Drug Treatment, had three levels: placebo, caffeine, and nicotine. This factor was studied according to a three-period placebo-controlled, double-blind, double dummy, cross-over design. Treatment order was balanced according to three Latin squares which were randomly assigned to blocks of six subjects. The second factor, Time After Scopolamine Administration, consisted of effect measures starting at 2, 4, and $6 \mathrm{~h}$ after scopolamine administration $\left(\mathrm{T}_{2}, \mathrm{~T}_{4}\right.$, and $\mathrm{T}_{6}$, respectively). The baseline measure taken $1 \mathrm{~h}$ before drug treatment was used as a covariate in order to correct for baseline differences.

A few days before the first experimental session, all subjects had individual training sessions in which they were shown and required to practice and to complete all the assessments and tasks used in the study. Then, the subjects participated in 3 study days which were spaced at least 1 week apart. The subjects were not allowed alcohol or other CNS drugs from $24 \mathrm{~h}$ before the testing sessions began. They were allowed a light caffeine-free (except for one cup of tea) breakfast and were provided lunch on the testing days. No beverages or food containing caffeine, theophylline, or theobromine (coffee, tea, cacao) were allowed during this time until the end of testing.

\section{Drug treatments}

On each occasion, scopolamine was injected subcutaneously in the back of the upper arm. The dose was $0.5 \mathrm{mg} / 75 \mathrm{~kg}$ body weight. On three occasions the subjects received chewing gum containing
Fig. 1 Time course of an experimental session. Assessments (above) and treatments (below). Numbers refer to hours after scopolamine administration

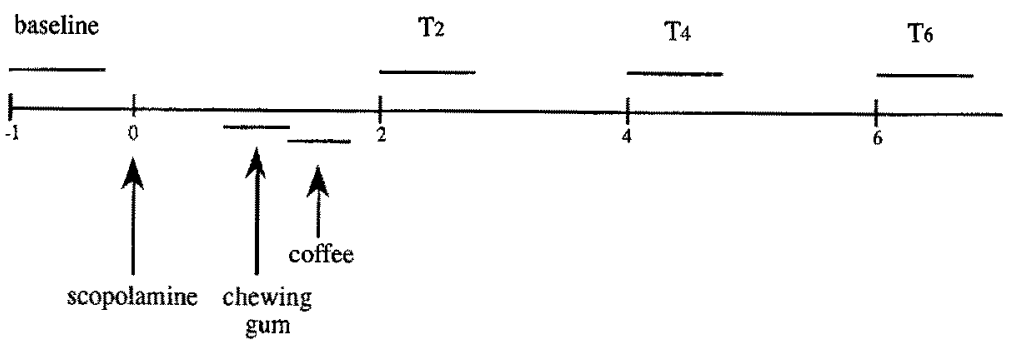


Table 1 Treatment conditions

PLA (scopolamine + placebo chewing gum + decaf)

NIC (scopolamine + nicotine chewing gum + decaf)

CAF (scopolamine + placebo chewing gum + coffee)

$2 \mathrm{mg}$ nicotine (Nicorette) or an identical looking placebo chewing gum and a coffee beverage containing $250 \mathrm{mg}$ caffeine or an identical looking decaffeinated beverage. Chewing gum was given $45 \mathrm{~min}$ after scopolamine. The subjects were instructed to chew the gum for $30 \mathrm{~min}$. Immediately thereafter, they received a thermos flask containing $390 \mathrm{ml}$ of freshly brewed filter coffee. Coffee was brewed using a Braun Aromaster 22 Compact Filter machine. Distilled water was used to prevent scaling in the coffee machine and to maintain a constant brew during the 3 -month study. The brew was made using $40 \mathrm{~g}$ filter ground coffee (Douwe Egberts Zilvermerk) per liter of water, yielding $910 \mathrm{ml}$ coffee. According to the manufacturer, this strenth of coffee would yield $643 \mathrm{mg}$ caffeine per liter coffee. In order to calibrate the procedure, samples were sent to the manufacturer to determine the amount of caffeine. The results showed that five different samples contained on average $636.5 \mathrm{mg}(\mathrm{SD}=4.5)$ of caffeine per liter coffee. Hence, each subject had to drink $390 \mathrm{ml}$ coffee (about three cups) in order to ingest $250 \mathrm{mg}$ caffeine. The decaffeinated coffee was brewed the same way using $40 \mathrm{~g}$ decaffeinated ground coffee (Douwe Egberts Decaf). The ingested amount of decaffeinated coffee would contain about $10 \mathrm{mg}$ caffeine. They were asked to drink the coffee within $30 \mathrm{~min}$.

\section{Assessments}

The cognitive test battery consisted of several tests that have been shown to be sensitive to the effects of aging (Houx 1991). The battery took approximately $45 \mathrm{~min}$ to complete. All cognitive assessments and the dependent variables are listed in Table 2. We made a distinction between primary and secondary cognitive outcome measures, because our hypothesis primarily aimed at testing memory effects. The primary outcome variables were measures of memory functions. The secondary outcome variables were measures of perceptual, attentional, psychomotor and executive functions. The following tests were used.

\section{Primary cognitive measures: memory tasks}

Word Learning Test (WLT) One of 12 parallel lists of 15 monosyllabic meaningful nouns matched for word frequency was presented at a rate of $2 \mathrm{~s}$ per word. The subjects were asked to read the words aloud as they appeared on a computer screen and to recall verbally as many words as possible as soon as the presentation stopped. This first immediate recall trial was followed by four more trials in which the same words were repeated in the same order. When the fifth trial was completed, the subjects performed the subsequent tasks and after 20 min were asked to recall as many of the previously learned words without prompting (delayed recall). The number of correctly recalled words was noted after each trial. The trial yielding the maximum number of recalled words was taken as the dependent variable (immediate recall). The delayed recall score was the number of words correctly recalled after $20 \mathrm{~min}$. A 30 -word list containing the initial 15-word list was presented after 20 min and after presentation of each word the subject had to respond "YES/NO" as fast as possible to indicate recognition of the word (delayed recognition). The reaction times were recorded.

According to the theory of signal detection (Pollack and Norman 1964), the proportion of correctly recognized words (cr) and the proportion of falsely recognized ( $\mathrm{fr}$ ) constitute the nonparametric sensitivity measure: $\mathrm{A}^{\prime}=1-1 / 4[\mathrm{fr} / \mathrm{cr}+[1-\mathrm{cr}] /[1-\mathrm{fr}]]$. $\mathrm{A}^{\prime}$ is in fact the proportion of correctly recognized words, corrected for the sub- ject's response tendency. Because the distribution of $\mathrm{A}^{\prime}$ is skewed due to a ceiling effect, $\mathrm{A}^{\prime}$ was arcsin transformed before it was used for statistical analysis.

Memory scanning The subjects were briefly shown a set of letters and told to memorize them. This is called the "memory set" (Sternberg 1969). The subjects then saw a series of 144 letters equally spaced in a matrix of 12 lines and 12 positions on a sheet of paper. Their task was to decide and respond, as rapidly as possible, by marking the letter with a pencil, whether or not each successive letter was one of those contained in the memory set. This task was performed with memory sets consisting of one, two, three, and four letters, respectively. Each test sheet contained 24 targets and 120 distractors. The total time needed by the subject to complete each sheet was timed with a stopwatch. Individual total time $\times$ set size functions were calculated. This function is defined by the equation $\mathrm{Tt}=\mathrm{A} * \mathrm{Ss}+\mathrm{B}$, in which $\mathrm{Tt}=$ total time, $\mathrm{A}=$ slope of the function (i.e. the amount of extra time needed per item in the memory set), $\mathrm{Ss}=$ size of the memory set, and $\mathrm{B}=$ intercept with the $\mathrm{Y}$-axis. The slope is a measure of the speed of scanning short term memory whereas the intercept measures sensorimotor speed.

\section{Secondary cognitive measures: perception, psychomotor and executive function}

Vistial search task Dots were presented on a computer screen in a random fashion. Every second two dots changed position. When four dots formed a square, the subject had to push a button as quickly as possible (within $2 \mathrm{~s}$ ). Efficient and rapid visual search is required to obtain a high signal-detection performance on this task. The perceptual sensitivity measure $A^{\prime}$ was taken as the dependent variable.

Motor choice reaction time task The subject held one button and was asked to press one of five other buttons located equidistantly from the hold button when lit. This yielded reaction times consisting of an initiation phase (time from stimulus onset until release of the hold button) and a movement phase (time from release of the hold button until the response button is pushed). The response set consisted of pressing the one button that lit up (simple RT), pressing one of three buttons which lit up (three-choice RT), or pressing the button to the right of the lit button (incompatible three-choice RT) as quickly as possible. Initiation times and movement times thus comprised the dependent variables obtained for each of the three reaction time tasks. This task measures sensorimotor speed, choice-reaction speed, and choice-reaction speed with response competition.

Stroop colour-word interference In subtest I, ten rows by ten columns of colour names (red, blue, green, and yellow) were printed in black on white cardboard. In subtest II, the same number of correspondingly coloured patches were printed, and in subtest III a number of colour names were printed in incongruously coloured ink. For instance, the word "green" could be printed in red. For card I, the subject was requested to "read the colour names row by row, as fast as possible, without making mistakes". The time needed to complete the whole card was recorded with a stopwatch. In the second subtest (card II) the instruction was "to name the coloured patches". The third trial (card III) involved naming the colour of the ink the colour words were printed in, without paying attention to the word itself. For each subtest the time taken to finish the card and the number and type of errors were recorded. Outcome parameters were: Reading $\left(t_{1}\right)$, Colour Naming $\left(t_{11}-t_{1}\right)$, and Interference $\left(t_{\mathrm{II}}-t_{\mathrm{II}}\right)$. The Stroop colour-word test is a well-known test for the ease of shifting perceptual sets to conform to changing task requirements, which is indicative of executive function. It also yields measures of reading speed and speed of naming colours. 
Table 2 Cognitive assessments

\begin{tabular}{llll}
\hline Test & Concept & Dependent variable & Units \\
\hline $\begin{array}{l}\text { Primary cognitive assessments (learning and memory) } \\
\text { Word learning }\end{array}$ & Primary memory & Immediate recall & \# of words \\
& Secondary memory & Delayed recall & \# of words \\
& Retrieval & Recognition sensitivity & proportion \\
& Speed of retrieval & Recognition RT & ms \\
Memory scanning & Speed of scanning in STM & Slope of scanning function & $\mathrm{s}$ \\
Secondary cognitive & assessments (information processing and psychomotor speed) & \\
Memory scanning & Sensorimotor speed & Intercept of scanning & $\mathrm{s}$ \\
Signal detection & Visual search & Perceptual sensitivity & proportion \\
Motor choice RT & Motor speed & Movement RT & ms \\
& Sensorimotor speed & Simple RT & ms \\
& Psychomotor speed & 3-choice RT & ms \\
Stroop & Response competition & Incompatible choice RT & ms \\
& Vocal motor speed & Reading time & $\mathrm{s}$ \\
Tapping & Symbol encoding & Color-naming time & $\mathrm{s}$ \\
\hline
\end{tabular}

Tapping The subject was required to finger-tap a response button as fast as possible during a short period of time (30 s). The number of taps per second is a measure of psychomotor speed. The test was carried out with the preferred hand.

\section{Physiological measures}

Pulse rate and blood pressure These were measured while the subject was in a relaxed sitting position before the start of each test battery, using an automated vital signs monitor (Dinamap $1800 \mathrm{BP}$; Critikon Inc., Tampa, Fla.).

Blood samples These were taken by venous puncture to assess concentrations of nicotine, cotinine (an active metabolite of nicotine), and caffeine. These were taken $2 \mathrm{~h}$ after scopolamine administration, i.e., 75 and $45 \mathrm{~min}$ after the start of nicotine and caffeine ingestion, respectively. The determinations of caffeine, nicotine and cotinine concentrations were performed by the Dept of Clinical Pharmacy of the University Hospital of Maastricht. The method employed was that of high resolution gaschromatography (H.R.G.C.). Detection limits were $<5 \mu \mathrm{g} / 1$ for both nicotine and cotinine. Quantification limits were $<10 \mu \mathrm{g} / 1$ for both nicotine and cotinine and $<200 \mu \mathrm{g} / 1$ for caffeine. Two independent determinations were made for each sample. Accuracy in series was $96.6 \%$, $97 \%$ and $94.3 \%(d f=6)$ for nicotine, cotinine and caffeine, respectively.

\section{Subjective assessments}

Mood was assessed by using the Bond and Lader (Bond and Lader 1974) Mood Rating Scale, which consists of 16 bipolar analogue scales with two opposed mood related adjectives at the ends of the scales. These have been shown to yield three mood factors, alertness, contentedness, and calmness. These factor scores were used as dependent variables, higher values representing greater amounts of each assessment. Subjectively experienced peripheral cholinergic side effects; dry mouth, blurred vision, and nausea were assessed the same way. The Blindness of the subjects towards nicotine and caffeine was checked by means of a Yes/No response to the questions: "Do you think your chewing gum contained nicotine? "and" Do you think your coffee contained caffeine?".
Statistical analysis

Dependent variables were analyzed separately in a repeated measures multivariate and univariate (MANOVA using SPSS 4.0 on MacIntosh) analysis of (co)variance, according to a 3 (treatment) $\times 3$ (time) factorial model to test the main effect of treatment and the treatment $\times$ time interaction, using baseline scores as covariates. Besides the multivariate tests, univariate a priori contrast comparisons were carried out between nicotine and placebo, and between cafieine and placebo, respectively. The latter were performed overall and separately at $\mathrm{T}_{2}, \mathrm{~T}_{4}$, and $\mathrm{T}_{6}$. These comparisons were made regardless of the outcome of the corresponding overall $F$ test. This is a legitimate procedure if the comparisons are built into the design or suggested by the theoretical basis of the experiment (Winer 1971). Correction for multiple testing was accomplished by using the "sequential Bonferron'" procedure for adjusting the $\alpha$-probability criterion (Overall and Rhoades 1987).

\section{Results}

The subjects could not tell whether they had ingested nicotine or caffeine. The Yes/No distribution was $9 / 7$ for nicotine and $8 / 8$ for caffeine.

Scopolamine adversely affected the performance of the subjects on nearly all tests, particularly the primary outcome measures recognition RT, immediate and delayed recall of word learning and slope of memory scanning, at $T_{2}$ and $T_{4}$. At $T_{6}$, there were still detrimental effects of scopolamine.

\section{Primary cognitive measures}

\section{Word learning}

The multivariate treatment effect on Immediate Recall was significant $\left(F_{3,13}=3.9, P<0.05\right)$. Both nicotine and caffeine significantly attenuated the effects of scopolamine on immediate recall $\left(F_{1,15}=5.4, P<0.05\right.$; $\left.F_{1,15}=6.2, \quad P<0.05\right)$. Mean paired comparisons 
Table 3 The means and standard errors of the primary outcome measures learning and memory functions, broken down by treat- ment (placebo, nicotine, caffeine) and Time after scopolamine administration (baseline, $T_{2}, T_{4}$, and $T_{6}$ )

\begin{tabular}{|c|c|c|c|c|c|c|}
\hline \multicolumn{3}{|c|}{ Time after scopolamine administration } & \multirow{2}{*}{$\frac{\text { Baseline }}{\text { Mean (SE) }}$} & \multirow{2}{*}{$\frac{\mathrm{T}_{2}}{\mathrm{Mean}(\mathrm{SE})}$} & \multirow{2}{*}{$\frac{T_{4}}{\text { Mean (SE) }}$} & \multirow{2}{*}{$\frac{\mathrm{T}_{6}}{\text { Mean }(\mathrm{SE})}$} \\
\hline & & + treatment & & & & \\
\hline \multirow[t]{12}{*}{ Word learning } & Immediate recall & scopolamine & $14.5(0.3)$ & $11.6(0.7)$ & $13.0(0.6)$ & $13.4(0.5)$ \\
\hline & \# of words correct & + nicotine & $14.4(0.2)$ & $12.6(0.7)$ & $13.2(0.5)$ & $13.9(0.5)$ \\
\hline & & + caffeine & $14.6(0.2)$ & $13.1(0.5)$ & $13.7(0.4)$ & $13.9(0.4)$ \\
\hline & Delayed recall & scopolamine & $13.1(0.6)$ & $8.2(1,0)$ & $10.6(0.9)$ & $11.4(0.8)$ \\
\hline & \# of words correct & + nicotine & $13.4(0.5)$ & $9.0(0.9)$ & $10.6(0.9)$ & $11.3(0.8)$ \\
\hline & & + caffeine & $13.3(0.4)$ & $8.7(0.8)$ & $11.8(0.7)$ & $12.5(0.7)$ \\
\hline & Delayed recogn. & scopolamine & $0.88(0.02)$ & $0.82(0.04)$ & $0.82(0.04)$ & $0.91(0.02)$ \\
\hline & Sensitivity & + nicotine & $0.88(0.03)$ & $0.86(0.05)$ & $0.84(0.04)$ & $0.88(0.04)$ \\
\hline & (proportion) & + caffeine & $0.91(0.02)$ & $0.91(0.02)$ & $0.86(0.02)$ & $0.92(0.02)$ \\
\hline & Recognition speed & scopolamine & $578(13)$ & $644(12)$ & $619(14)$ & $604(12)$ \\
\hline & $\mathrm{RT}(\mathrm{ms})$ & + nicotine & $580(15)$ & $635(22)$ & $603(16)$ & $591(13)$ \\
\hline & & + caffeine & $575(15)$ & $615(12)$ & $606(11)$ & $591(11)$ \\
\hline \multirow[t]{6}{*}{ Memory scanning } & Slope & scopolamine & $10.2(1.2)$ & $14.4(1.3)$ & $13.7(1.4)$ & $14.0(1.5)$ \\
\hline & time (s) & + nicotine & $10.2(0.8)$ & $12.0(1.1)$ & $12.6(1.3)$ & $13.4(1.0)$ \\
\hline & & + caffeine & $10.3(1.2)$ & $13.6(1.5)$ & $12.0(1.3)$ & $13.6(1.0)$ \\
\hline & Intercept & scopolamine & $19.8(0.9)$ & $20.8(1.2)$ & $22.1(1.0)$ & $20.2(1.0)$ \\
\hline & time (s) & + nicotine & $18.8(0.9)$ & $21.1(1.3)$ & $22.5(1.0)$ & $19.6(1.0)$ \\
\hline & & + caffeine & $19.4(0.8)$ & $19.2(1.1)$ & $23.3(1.3)$ & $19.3(1.1)$ \\
\hline
\end{tabular}
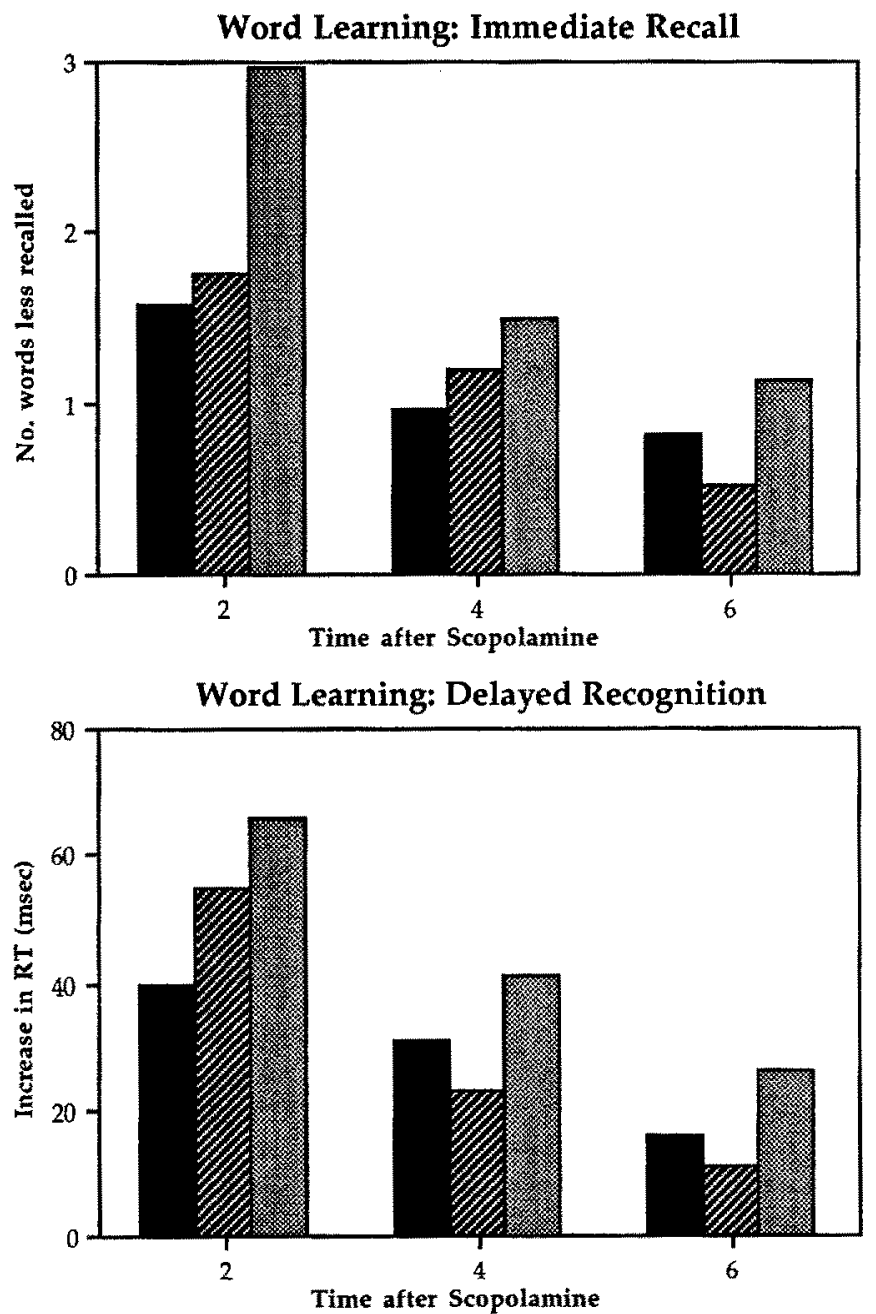

Fig. 2 Memory effects of scopolamine + caffeine (black bars), scopolamine+nicotine (diagonally striped bars), and scopolamine + placebo
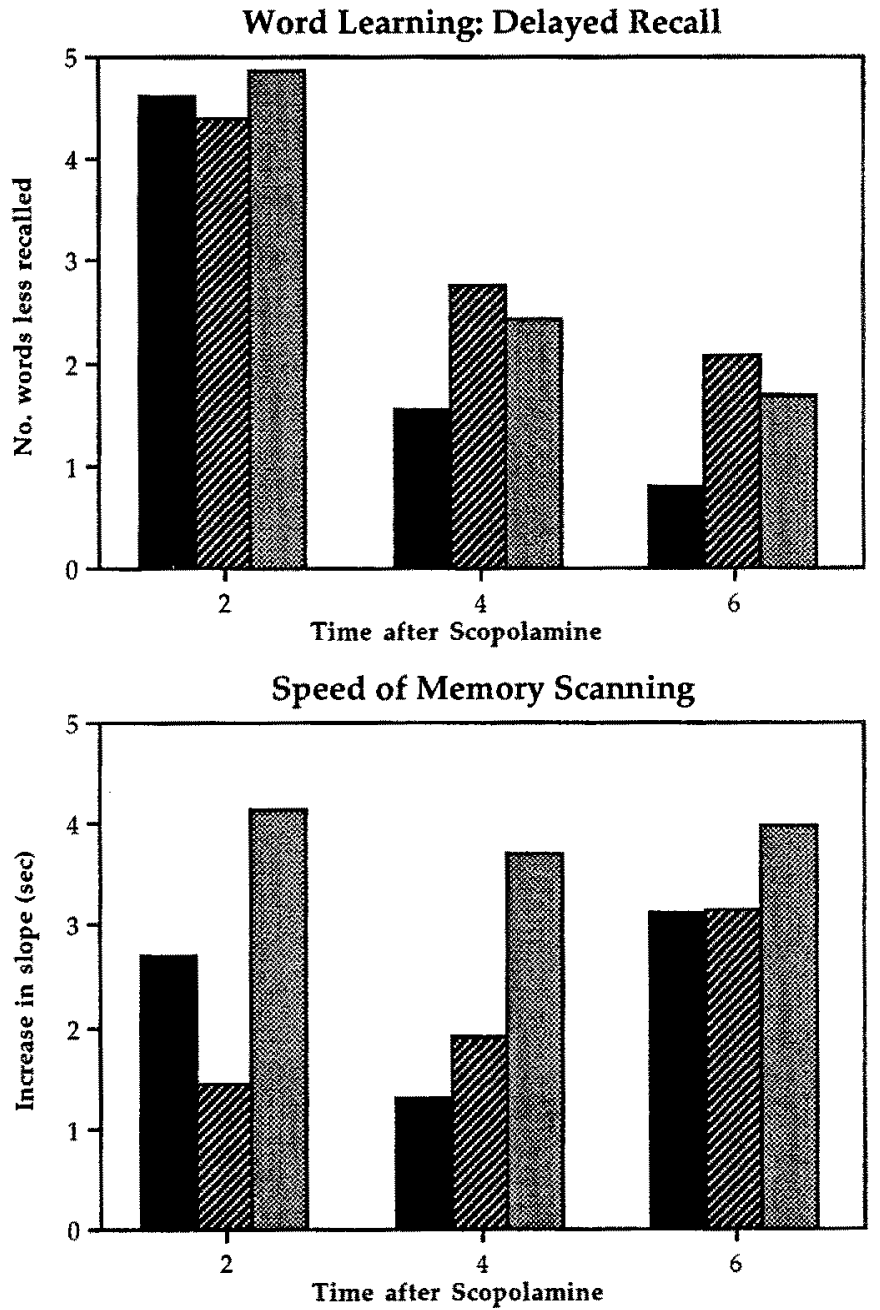

(grey bars) at $\mathrm{T}_{2}, \mathrm{~T}_{4}$, and $\mathrm{T}_{6}$ expressed as deviations from baseline scores. Height of bars corresponds with degree of impairment 
Table 4 The means and standard errors of the secondary outcome measures perceptual, psychomotor and executive functions, broken down by Treatment and Time after scopolamine administration

\begin{tabular}{|c|c|c|c|c|c|c|}
\hline \multicolumn{3}{|c|}{ Time after scopolamine administration } & \multirow{2}{*}{$\frac{\text { Baseline }}{\text { Mean (SE) }}$} & \multirow{2}{*}{$\frac{\mathrm{T}_{2}}{\text { Mean (SE) }}$} & \multirow{2}{*}{$\frac{\mathrm{T}_{4}}{\text { Mean (SE) }}$} & \multirow{2}{*}{$\frac{\mathrm{T}_{6}}{\text { Mean }(\mathrm{SE}}$} \\
\hline & & + treatment & & & & \\
\hline Visual search & $\begin{array}{l}\text { Perceptual } \\
\text { Sensitivity } \\
\text { (proportion) }\end{array}$ & $\begin{array}{l}\text { scopolamine } \\
+ \text { nicotine } \\
+ \text { caffeine }\end{array}$ & $\begin{array}{l}0.89(0.02) \\
0.88(0.03) \\
0.90(0.02)\end{array}$ & $\begin{array}{l}0.82(0.04) \\
0.83(0.03) \\
0.86(0.02)\end{array}$ & $\begin{array}{l}0.83(0.03) \\
0.82(0.04) \\
0.87(0.03)\end{array}$ & $\begin{array}{l}0.85(0.03) \\
0.85(0.04) \\
0.89(0.02)\end{array}$ \\
\hline Choice reaction & $\begin{array}{l}\text { Response competing } \\
\text { 3-choice RT (ms) } \\
\text { Movement time } \\
\text { (ms) }\end{array}$ & $\begin{array}{l}\text { scopolamine } \\
\text { + nicotine } \\
\text { + caffeine } \\
\text { scopolamine } \\
\text { + nicotine } \\
\text { + caffeine } \\
\text { scopolamine } \\
\text { + nicotine } \\
\text { + caffeine } \\
\text { scopolamine } \\
\text { + nicotine } \\
\text { + caffeine }\end{array}$ & $\begin{array}{l}281(4) \\
278(5) \\
275(4) \\
324(6) \\
329(8) \\
316(6) \\
396(12) \\
394(15) \\
386(10) \\
102(3) \\
106(3) \\
102(3)\end{array}$ & $\begin{array}{l}297(6) \\
295(7) \\
293(7) \\
352(9) \\
351(12) \\
333(9) \\
423(15) \\
409(15) \\
426(16) \\
122(5) \\
123(5) \\
116(4)\end{array}$ & $\begin{array}{l}288(7) \\
284(6) \\
282(6) \\
350(10) \\
341(8) \\
340(8) \\
421(16) \\
411(15) \\
412(14) \\
118(5) \\
122(6) \\
115(4)\end{array}$ & $\begin{array}{l}276(6) \\
273(6) \\
276(6) \\
333(10) \\
329(6) \\
333(9) \\
405(15) \\
398(14) \\
396(14) \\
118(5) \\
113(5) \\
114(4)\end{array}$ \\
\hline Stroop & $\begin{array}{l}\text { Reading } \\
\text { time (s) } \\
\text { Color naming } \\
\text { extra time (s) } \\
\text { Interference } \\
\text { extra time (s) }\end{array}$ & $\begin{array}{l}\text { scopolamine } \\
\text { + nicotine } \\
\text { + caffeine } \\
\text { scopolamine } \\
\text { + nicotine } \\
\text { + caffeine } \\
\text { scopolamine } \\
\text { + nicotine } \\
\text { + caffeine }\end{array}$ & $\begin{array}{l}34.3(1.2) \\
34.7(1.0) \\
34.5(0.8) \\
11.4(1.4) \\
11.0(1.4) \\
9.9(1.4) \\
20.2(1.5) \\
15.4(1.5) \\
19.6(2.2)\end{array}$ & $\begin{array}{l}36.5(1.3) \\
36.0(1.3) \\
35.0(1.2) \\
12.8(1.5) \\
10.2(1.4) \\
11.6(1.6) \\
23.7(2.5) \\
23.9(1.5) \\
23.8(2.2)\end{array}$ & $\begin{array}{l}35.4(1.4) \\
35.0(1.1) \\
34.6(1.2) \\
9.6(1.3) \\
11.1(1.7) \\
9.5(1.3) \\
23.1(1.8) \\
21.6(1.9) \\
25.0(3.4)\end{array}$ & $\begin{array}{l}35.3(1.3) \\
34.3(1.2) \\
34.0(0.9) \\
10.2(0.8) \\
10.6(1.2) \\
9.1(1.5) \\
22.8(2.6) \\
19.4(1.6) \\
23.1(2.5)\end{array}$ \\
\hline Tapping & $\begin{array}{l}\text { Preferred hand } \\
\text { \# of taps/s }\end{array}$ & $\begin{array}{l}\text { scopolamine } \\
+ \text { nicotine } \\
+ \text { caffeine }\end{array}$ & $\begin{array}{l}6.85(0.08) \\
6.78(0.05) \\
6.92(0.09)\end{array}$ & $\begin{array}{l}6.25(0.08) \\
6.24(0.08) \\
6.37(0.10)\end{array}$ & $\begin{array}{l}6.35(0.09) \\
6.36(0.11) \\
6.57(0.09)\end{array}$ & $\begin{array}{l}6.64(0.08) \\
6.66(0.06) \\
6.71(0.09)\end{array}$ \\
\hline
\end{tabular}

revealed that this effect was mainly due to a significant decrease in the effect of scopolamine at $\mathrm{T} 2$ elicited by nicotine $\left(F_{1,15}=5.0, \quad P<0.05\right)$ and by caffeine $\left(F_{\mathrm{l}, 15}=6.5, P=0.05\right)$.

There was no multivariate effect of treatment on Delayed Recall. Nicotine had no effect on the scopolamine-induced impairment of delayed recall, whereas caffeine attenuated the scopolamine-induced impairment of delayed free recall at $\mathrm{T}_{6}\left(F_{1,15}=9.8, P<0.01\right.$; see also Fig. 2).
The multivariate treatment effect on recognition RT was not significant. Nicotine had no effect on recognition parameters. Overall, caffeine significantly attenuated the scopolamine-induced decrease in the speed of delayed recognition $\left(F_{1,15}=4.5, P<0.05\right)$. This was mainly due to its significant attenuation of the scopolamine-induced slowing of word recognition RT $\left(F_{1,15}=9.4, P<0.01\right)$ and its reversal of the scopolamine-impaired delayed recognition sensitivity at $\mathrm{T}_{2}$ $\left(F_{1,15}=7.8, P=0.05\right)$.

Table 5 The means and standard errors of the physiological measures, broken down by Treatment and Time after scopolamine administration

\begin{tabular}{|c|c|c|c|c|c|c|}
\hline \multicolumn{3}{|c|}{ Time after scopolamine administration } & \multirow{2}{*}{$\frac{\text { Baseline }}{\text { Mean (SE) }}$} & \multirow{2}{*}{$\frac{\mathrm{T}_{2}}{\text { Mean (SE) }}$} & \multirow{2}{*}{$\frac{\mathrm{T}_{4}}{\operatorname{Mean}(\mathrm{SE})}$} & \multirow{2}{*}{$\frac{\mathrm{T}_{6}}{\text { Mean }(\mathrm{SE})}$} \\
\hline & & + treatment & & & & \\
\hline \multirow[t]{6}{*}{ Blood pressure } & Systolic & scopolamine & $126.3(2.5)$ & $113.6(2.6)$ & $113.2(2.4)$ & $111.4(3.1)$ \\
\hline & $(\mathrm{mm} \mathrm{Hg})$ & + nicotine & $120.9(2.2)$ & $115.9(2.8)$ & $116.8(2.1)$ & $112.3(2.5)$ \\
\hline & & + caffeine & $123.7(2.2)$ & $118.3(2.9)$ & $120.2(2.7)$ & $118.6(2.5)$ \\
\hline & Diastolic & scopolamine & $61.1(2.0)$ & $57.7(3.2)$ & $50.7(2.0)$ & $52.3(2.2)$ \\
\hline & $(\mathrm{mm} \mathrm{Hg})$ & + nicotine & $60.8(2.6)$ & $57.3(2.4)$ & $52.4(2.0)$ & $52.9(2.3)$ \\
\hline & & + caffeine & $60.9(2.3)$ & $60.6(2.3)$ & $53.4(2.2)$ & $54.6(1.9)$ \\
\hline \multirow[t]{3}{*}{ Heart rate } & Beats/min & scopolamine & $68.2(2.5)$ & $52.3(2.0)$ & $57.8(2.2)$ & $57.6(2.0)$ \\
\hline & & + nicotine & $67.7(2.9)$ & $56.4(3.0)$ & $60.4(3.1)$ & $60.3(2.9)$ \\
\hline & & + caffeine & $66.6(3.3)$ & $51.1(2.0)$ & $55.4(1.8)$ & $55.9(1.8)$ \\
\hline
\end{tabular}


Table 6 The means and standard errors of the subjective assessments, broken down by Treatment and Time after scopolamine administration

\begin{tabular}{|c|c|c|c|c|c|c|}
\hline \multicolumn{3}{|c|}{ Time after scopolamine administration } & \multirow{2}{*}{$\frac{\text { Baseline }}{\text { Mean (SE) }}$} & \multirow{2}{*}{$\frac{\mathrm{T}_{2}}{\operatorname{Mean}(\mathrm{SE})}$} & \multirow{2}{*}{$\frac{\mathrm{T}_{4}}{\text { Mean }(\mathrm{SE})}$} & \multirow{2}{*}{$\frac{T_{6}}{\text { Mean }(\mathrm{SE})}$} \\
\hline & & + treatment & & & & \\
\hline \multirow[t]{9}{*}{ Peripheral effects } & Dry mouth & scopolamine & $35.7(5.7)$ & $80.8(5.7)$ & $56.9(4.7)$ & $44.3(5.7)$ \\
\hline & $(0-100)$ & + nicotine & $32.3(4.9)$ & $78.2(5.7)$ & $58.2(5.5)$ & $45.3(6.1)$ \\
\hline & $(r=0.70)$ & + caffeine & $32.5(5.9)$ & $84.8(3.6)$ & $58.4(7.5)$ & $43.6(5.7)$ \\
\hline & Blurred vision & scopolamine & $16.9(4.4)$ & $51.4(7.2)$ & $44.5(8.8)$ & $38.0(8.4)$ \\
\hline & $(0-100)$ & + nicotine & $24.7(5.5)$ & $54.4(6.7)$ & $50.1(7.9)$ & $44.7(7.2)$ \\
\hline & $(r=0.85)$ & + caffeine & $19.1(4.9)$ & $47.0(8.0)$ & $46.1(8.5)$ & $43.0(8.5)$ \\
\hline & Nausea & scopolamine & $15.7(4.4)$ & $49.0(5.4)$ & $41.6(6.9)$ & $34.4(5.5)$ \\
\hline & $(0-100)$ & + nicotine & $19.0(4.4)$ & $44.3(7.5)$ & $44.3(5.7)$ & $43.7(8.2)$ \\
\hline & $(r=0.59)$ & + caffeine & $23.0(5.0)$ & $63.9(7.2)$ & $39.1(6.4)$ & $44.1(7.9)$ \\
\hline \multirow[t]{9}{*}{ Mood scales } & Alertness & scopolamine & $65.2(4.4)$ & $40.7(2.7)$ & $47.1(3.8)$ & $47.9(3.6)$ \\
\hline & $(0-100)$ & + nicotine & $67.4(3.5)$ & $35.5(4.1)$ & $43.5(4.1)$ & $49.6(3.9)$ \\
\hline & $(r=0.56)$ & + caffeine & $73.5(3.0)$ & $41.4(3.5)$ & $49.5(4.2)$ & $52.7(3.5)$ \\
\hline & Contentment & scopolamine & $69.0(3.3)$ & $63.4(3.3)$ & $64.6(3.8)$ & $67.9(3.5)$ \\
\hline & $(0-100)$ & + nicotine & $74.7(3.5)$ & $60.7(3.3)$ & $64.0(3.7)$ & $65.1(3.5)$ \\
\hline & $(r=0.53)$ & + caffeine & $75.3(3.1)$ & $65.4(3.6)$ & $68.2(3.5)$ & $68.8(4.1)$ \\
\hline & Calmness & scopolamine & $72.4(4.8)$ & $64.2(4.8)$ & $67.3(3.0)$ & $69.3(3.2)$ \\
\hline & $(0-100)$ & + nicotine & $71.8(4.0)$ & $68.3(3.8)$ & $65.4(3.5)$ & $60.8(4.2)$ \\
\hline & $(r=0.57)$ & + caffeine & $72.5(3.1)$ & $64.8(3.8)$ & $69.8(3.7)$ & $65.2(4.3)$ \\
\hline
\end{tabular}

\section{Memory scanning}

There was no multivariate treatment effect on speed of memory scanning. Overall, nicotine significantly attenuated the scopolamine-induced slowing of memoryscanning $\left(F_{1,15}=6.1, P<0.05\right)$. This was mainly due to its significant reduction of the scopolamine-induced increased slope of memory scanning at $T_{2}\left(F_{1.15}=13.2\right.$, $P<0.005)$. Caffeine did not affect this parameter.

\section{Secondary cognitive measures}

\section{Visual search}

Nicotine did not affect this parameter. Overall, caffeine attenuated the scopolamine-induced decrement in perceptual sensitivity of visual search $\left(F_{1,15}=6.5\right.$, $P<0.05$ ). This was probably due to its attenuation of the scopolamine-induced impairment at $T_{4}$ and $T_{6}$, respectively. This effect was not statistically significant.

\section{Motor choice reaction time}

Nicotine significantly attenuated the scopolamineinduced slowing of the initiation time in the incompatible three-choice RT task at $\mathrm{T}_{2}\left(F_{1,15}=13.7\right.$, $P<0.005)$. Nicotine had no effect on either the initiation time or the movement time which was slowed by scopolamine in the simple RT and choice RT tasks. Caffeine had no effect on any of the scopolamineinduced decrements in simple RT, choice RT, and incompatible choice RT.

\section{Stroop}

Nicotine significantly reversed the slowing effect of scopolamine on colour-naming time at $\mathrm{T}_{2}\left(F_{1,15}=6.7\right.$, $P<0.05)$. Nicotine had no effect on reading time and interference. Caffeine attenuated the scopolamineinduced slowing of reading time at $\mathrm{T}_{2}\left(F_{1.15}=12.2\right.$, $P<0.005$ ), but had no effect on colour-naming time and interference.

\section{Tapping}

Nicotine did not affect the finger-tapping rate. The scopolamine-induced decrease in the number of taps per second was significantly attenuated by caffeine at $\mathrm{T}_{4}\left(F_{1,15}=6.4, P=0.05\right)$.

\section{Vital signs}

\section{Blood pressure and heart rate}

There was a multivariate effect of treatment on systolic blood pressure $\left(F_{3,13}=6.4, P<0.05\right)$. Nicotine did not significantly affect any of the scopolamine-induced alterations of cardiovascular parameters. Caffeine significantly attenuated the scopolamine-induced decrease in systolic blood pressure $\left(F_{1,15}=14.3\right.$, $P<0.005)$, at $\mathrm{T}_{4} \quad\left(F_{1,15}=8.9, \quad P<0.01\right)$ and $\mathrm{T}_{6}$ $\left(F_{1,15}=18.9, P<0.001\right)$, but had no effect on the scopolamine-induced decrease in diastolic blood pressure and heart rate. 
Table 7 Comparison of the magnitude of effects of different cognition enhancing substances on the scopolamine-induced memory deficit on immediate and delayed recall of word lists. Buschke selective reminding procedure (only words not recalled are presented in acquisition trials), LTR long term recall (the number of words that are recalled on two consecutive trials), $n$ selective reminding procedure was done until the whole list was remembered on six consecutive occasions, Rey repeated acquisition trials (immediate recall: IR) followed by a delayed recall trial (DR) without presentation

\begin{tabular}{|c|c|c|c|c|c|c|c|c|c|}
\hline $\begin{array}{l}\text { Study substance } \\
\text { and dosage }\end{array}$ & $\begin{array}{l}\text { Scop. dose } \\
\text { formulation }\end{array}$ & $\begin{array}{l}\text { Time } \\
\text { after Scop }\end{array}$ & $\begin{array}{l}\text { Memory Test } \\
\text { (words/trials) }\end{array}$ & Recall & $\begin{array}{l}\text { Baseline } \\
\text { Score }\end{array}$ & $\begin{array}{l}\text { Scop. } \\
\text { deficit }\end{array}$ & $\begin{array}{l}\text { attent } \\
\text { abs }\end{array}$ & $\begin{array}{l}\text { ation } \\
\text { rel }\end{array}$ & Reference \\
\hline Aniracetam $1500 \mathrm{mg}$ & $0.7 \mathrm{mg} \mathrm{SC}$ & $3 \mathrm{~h} 20^{\prime}$ & Buschke $(14 / n)$ & LTR & 35.3 & 20.9 & 2.7 & $* 13 \%$ & (Wesnes et al. 1990) \\
\hline TRH $0.5 \mathrm{mg} / \mathrm{kg} \mathrm{IV}$ & $0.5-0.75 \mathrm{mg}$ IV & $1 \mathrm{~h} 30^{\prime}$ & Buschke (12/8) & IR & 9.3 & 3.4 & 1.1 & $* 32 \%$ & (Molchan et al. 1990) \\
\hline Nicotine $1.5 \mathrm{mg}$ PO & $1.2 \mathrm{mg} \mathrm{PO}$ & $1 \mathrm{~h} 30^{\prime}$ & Rey $(10 / 4)$ & $\mathrm{IR}$ & 8.3 & 0.7 & 0.2 & $29 \%$ & $\begin{array}{l}\text { (Rusted and Eaton- } \\
\text { Williams 1991) }\end{array}$ \\
\hline- & -.. & $1 \mathrm{~h} 30^{\prime}$ & Rey (30/4) & $\mathrm{IR}$ & 16.1 & 2.1 & -0.1 & $-5 \%$ & \\
\hline Oxiracetam $800 \mathrm{mg}$ & $0.5 \mathrm{mg} \mathrm{SC}$ & $3 \mathrm{~h}$ & Rey $(20 / 3)$ & IR & 31.2 & 13.5 & 1.8 & $13 \%$ & (Preda et al. 1993) \\
\hline- & - & $3 h$ & - & DR & 13.5 & 7.8 & 2.5 & $* 32 \%$ & \\
\hline Oxiracetam $1600 \mathrm{mg}$ & - & $3 \mathrm{~h}$ & - & IR & 31.2 & 13.5 & 2.7 & $20 \%$ & \\
\hline- & $-\cdots$ & $3 \mathrm{~h}$ & - & DR & 13.5 & 7.8 & 4.8 & $* 62 \%$ & \\
\hline Nicotine $2 \mathrm{mg}$ & $0.5 \mathrm{mg} / 75 \mathrm{~kg} \mathrm{SC}$ & $2 \mathrm{~h}$ & Rey $(15 / 5)$ & IR & 14.5 & 2.9 & 1.1 & $* 38 \%$ & (this study) \\
\hline- & - & $2 \mathrm{~h}$ & - & DR & 13.1 & 4.9 & 0.5 & $10 \%$ & \\
\hline Caffeine $250 \mathrm{mg}$ & $\ldots$ & $2 \mathrm{~h}$ & - & $\mathrm{IR}$ & 14.5 & 2.9 & 1.4 & $* 48 \%$ & \\
\hline- & - & $2 \mathrm{~h}$ & - & DR & 13.1 & 4.9 & 0.3 & $6 \%$ & \\
\hline
\end{tabular}

* This attenuation was significant

Subjective measures

\section{Peripheral side effects and mood scales}

Scopolamine-induced side-effect and mood ratings were not significantly affected by nicotine or caffeine.

\section{Blood levels}

\section{Blood levels}

The mean blood level of caffeine was $5339 \mu \mathrm{g} / 1$ in the caffeine condition, but 775 and $737 \mu \mathrm{g} / 1$ in the nicotine and placebo conditions, respectively. The difference was highly significant $\left(F_{2.14}=68.2, \quad P<0.0001\right)$. Cotinine blood levels were not significantly different $(129,126$, and $113 \mu \mathrm{g} / 1$ in the nicotine, placebo, and caffeine conditions, respectively). Nicotine was detected in only 6 of the 16 subjects who received nicotine chewing gum and was detected 4 of the 32 times that placebo chewing gum was administered.

The nicotine and cotinine blood levels over the various conditions did not seem very clearly to confirm the presence of nicotine administered via chewing gum. However, the low incidence of detection of nicotine in the blood after the administration of nicotine $2 \mathrm{mg}$ in chewing gum, can be explained to a great deal. Benowitz et al. (1988) showed that the administration of nicotine $4 \mathrm{mg}$ chewing gum yielded a curve with nicotine concentrations varying between 7 and $11 \mu \mathrm{g} / 1$ from 30 to $90 \mathrm{~min}$ after the end of the administration period. In our study, blood was taken 45 min after the end of the chewing period. Since we administered only $2 \mathrm{mg}$ nicotine, we might expect, roughly, blood nicotine concentrations between 3.5 and $5.5 \mu \mathrm{g} / 1$ if we divide those reported by Benowitz et al. by 2 . However, our detection limit of nicotine in the blood was $5 \mu \mathrm{g} / 1$ and the quantification limit was $10 \mu \mathrm{g} / \mathrm{l}$. Of the six correct nicotine detections only one was $>10 \mu \mathrm{g} / 1$ $(12.7 \mu \mathrm{g} / 1)$ and of the four false nicotine detections none were $>10 \mu \mathrm{g} / 1$. So, with respect to the detection of nicotine, the results do not seem to deny the absorption of nicotine. The nicotine dose administered was a very small one and therefore difficult to detect with the method used. On the other hand, in order to explain the four faulty detections of nicotine, we have to ask ourselves the question whether this could have been caused by high nicotine levels obtained during the previous day, or whether we can prove with reasonable certainty that this was caused by a protocol violation, i.e. smoking before the experiment began. With regards to the latter, there was continuous supervision of the subjects starting $3 \mathrm{~h}$ before the blood sample was taken, i.e. $1 \mathrm{~h}$ before scopolamine and $2 \mathrm{~h}$ before the active treatment was administered. The possibility of smoking before that time cannot be excluded, however. Neither can it be excluded that smoking during the previous day led to the detection of nicotine in the blood. Nicotine, which has a half-life of $2 \mathrm{~h}$, accumulates over the first $6-8 \mathrm{~h}$ of regular smoking, and persists at significant levels for $6-8 \mathrm{~h}$ after cessation, which is overnight if a smoker continues to smoke until bedtime (Surgeon General 1988). Smoking ten cigarettes in the evening may in this manner lead to a (faulty) detection of nicotine the next day. Cotinine has a halflife of $19 \mathrm{~h}$, and hence its levels may reflect smoking habits much more than they may reflect absorption of the treatment administered. In fact, the correlations of cotinine blood levels with the reported number of cigarettes smoked daily (varying from 2 to 10 ), appeared to be $0.75(P<0.001), 0.71 \quad(P<0.005)$, and 0.68 $(P<0.005)$ in the placebo, caffeine, and nicotine conditions, respectively. 


\section{Effect of treatment order}

The possibility that learning effects over the sessions influenced the results needs to be considered because the intended complete order balancing of the design was compromised by the two subjects that dropped out. If learning had taken place, it could possibly explain some of the drug effects, particularly the effect of caffeine upon delayed recall, in which performance after caffeine appeared to return to baseline sooner than after nicotine and placebo. Did the learning effect increase the baseline? We studied this possibility as follows.

The distribution of treatment order over sessions $1 / 2 / 3$ yielded $n=5 / 5 / 6$ for both caffeine and nicotine and $n=6 / 6 / 4$ for placebo. When caffeine was administered at the first or second session, the baseline score 1 week later was taken as a "reversal to baseline score". The same procedure was applied to construct the nicotine and placebo "reversal to baseline scores". It transpired that baseline scores of delayed recall had increased over 1 week for placebo (1.0), nicotine (0.9), and caffeine (1.2). This means that a learning effect over 1 week had indeed occurred but the difference between drug conditions was only minimal, indicating that not only the caffeine baseline but also the placebo baseline increased.

We also analyzed the "reversal to baseline scores" for immediate recall (placebo: 0.3 ; nicotine: 0.6 ; caffeine: 0.1 ) and slope of memory scanning (placebo: 0.8 ; nicotine: -0.5 ; caffeine: 0.9 ). The difference between placebo and nicotine in the latter would amplify rather than diminish the effect of nicotine observed at $\mathrm{T}_{2}$ for this parameter. Therefore we concluded that very small learning effects might have occurred, but that they did not influence the results pertaining to the caffeine- and nicotine-placebo comparisons.

\section{Effect sizes}

The treatment effects of caffeine and nicotine were significant on several parameters, but the size of these effects was generally small. Because the treatment effects of caffeine and nicotine were both significant for the immediate recall of the 15-word list, and because most studies investigating cognition enhancers with the scopolamine model have used word lists, we set out to compare the magnitudes of these results with those obtained in similar scopolamine studies. The result of this comparison is listed in Table 7. We calculated the absolute difference scores and percentages of change obtained after the administration of a putative cognitive enhancer to combat the effects of scopolamine. Since different studies use different word lists with different lengths and different amounts of presentation trials, some difficulties may arise as to the comparison of absolute values of treatment effects. As can be con- cluded from the results shown in Table 7, the absolute attenuation scores of the scopolamine-induced deficits in word recall obtained in our study after caffeine and nicotine are indeed small, but do not deviate drastically from (significant) results obtained in other studies with putative cognitive enhancers such as the neuropeptide TRH (Molchan et al. 1990), and the nootropic substances aniracetam (Wesnes et al. 1990), and oxiracetam (Preda et al. 1993).

\section{Discussion}

To the best of our knowledge, this is the first study demonstrating the effects of caffeine on memory in humans, as assessed with the scopolamine model of cholinergic blockade.

Before further interpreting the effects, several issues need to be addressed. First, the size of the treatment effect. As was shown in Table 7, the effect sizes of caffeine and nicotine in immediate recall memory were rather small, but there have been several other similar studies reporting effect sizes that were within the same range. Several factors influence the size of the treatment effect. The size of the scopolamine effect is probably determined by the dosage given and also by its route of administration. It is likely that the fairly large scopolamine effect in the study by Wesnes et al. (1990) was associated with the relatively high dose of scopolamine. The larger the scopolamine effect, the more room for improvement to be induced by a cognitive enhancing substance. The other major factor that determines the size of treatment effects is the presence of ceiling effects in the tests used. It is fairly obvious that the immediate recall score obtained in the baseline condition of our study could hardly be improved further. Rusted and Eaton-Williams (1991) showed that longer word lists of 30 , rather than 10 words, permit greater sensitivity for measuring improving effects of nicotine. However, we did not intend to measure cognition enhancing effects of nicotine and caffeine per se, but only those apparent as an attenuation of the scopolamine effect and hence the sensitivity of our method wholly depended on the presence, and size, of scopolamine effects. For that reason a true ceiling effect was perhaps only apparent in the measure of recognition sensitivity, with which the scopolamine effect was small and hence did not leave much room for attenuation. Surprisingly, on this measure, a statistically significant effect of caffeine was found. So, eventual ceiling effects apparently did not render the design insensitive. However, it is difficult to generalize from small significant effects, to any clinically relevant ones. For that reason, the most important finding among the results presented here is the novelty of the finding of caffeine's effect on memory in the scopolamine paradigm. In future studies on the memory enhancing effects of caffeine, we should take factors associated 
with effect size, such as the possibility of ceiling effects and word list length, into account. Another important point concerning the impact of even a small significant effect of caffeine on memory performance is that caffeine is consumed daily, through the consumption of coffee and tea, by millions of people all over the world (Klatsky et al. 1993).

The question of whether we had a real nicotine condition is an important one, because of the difficulty in discriminating nicotine from placebo on the basis of nicotine and cotinine blood concentrations. Since it cannot be excluded that subjects did actually smoke on the morning before the experiment, perhaps measures ought to be taken in future experiments to prevent this problem. We tried to do this by selecting irregular smokers. The reason was threefold. Firstly, it was considered unethical to administer nicotine to people who never used it. Secondly, subjects had to be familiar with the effects of nicotine, to a certain extent, to avoid adverse effects. Thirdly, subjects had to be used to abstaining from nicotine for a relatively long period. We thought this would only be possible in subjects who have a very low frequency of habitual use. It was difficult to find enough subjects who would fulfil the criterion of smoking no more than five cigarettes per day and therefore we decided to include subjects with reported smoking frequencies of up to ten cigarettes per day. To prevent the nicotine detection problem in future experiments of this kind, it might be better to pursue the subject inclusion criterion of a maximum reported smoking frequency of no more than five cigarettes per day. The question whether we had a real nicotine condition is in the end answered by the performance data. There was evidently an active nicotine condition, but it could have been better.

It appeared that the effects of nicotine were present at $T_{2}$ only while those of caffeine were distributed over $\mathrm{T}_{2}, \mathrm{~T}_{4}$, and $\mathrm{T}_{6}$. The lack of effect of nicotine at $\mathrm{T}_{4}$ and $\mathrm{T}_{6}$ is probably due to its shorter half-life (Gilman et al. 1990). Furthermore, it is possible that the effects of caffeine last longer than those of scopolamine and hence some effects of caffeine emerge at $T_{4}$ and $T_{6}$. This is most clearly seen with the caffeine-induced reversal of the scopolamine-induced decrease in systolic blood pressure at $T_{4}$ and $T_{6}$ and with the caffeine-induced attenuation of the scopolamine-induced delayed recall deficit in word learning.

The memory enhancing effects of caffeine were of a different nature than those of nicotine. Caffeine had a more pronounced effect on parameters reflecting speed and quality of delayed recognition of learned words, whereas nicotine seemed to facilitate working memory capacity, as seen by its attenuation of scopolamineinduced slowing of rate of memory scanning and incompatible choice reaction time. Most behavioral studies on the effects of caffeine in humans have suggested that caffeine acts as a CNS stimulant. However, the specificity, in terms of amnesic relative to its seda- tive effects, of the scopolamine model has been queried (Rusted and Eaton-Williams 1991). Despite this, the most pronounced effects of scopolamine on behaviour are consistently reported to be on memory function. Although we found scopolamine to have marked effects on non-memory parameters, such as tapping rate and movement time in choice reaction, the rather pronounced effects of scopolamine on immediate and delayed recall and recognition as well as on the rate of memory scanning seem to confirm the effects of scopolamine on memory processes as reported in the literature.

If caffeine were to act primarily as a CNS stimulant, one would have anticipated a different pattern of results, i.e., a more pronounced attenuation of the scopolamine-induced slowing of the finger-tapping rate, because caffeine alone is reported specifically to increase the rate of finger tapping (Fagan et al. 1988; Swift and Tiplady 1988), and also an attenuation of the scopolamine-induced increase in movement time in the reaction time tasks. Caffeine would have been expected to increase speed in cognition tests rather than improve qualitative scores of cognitive performance, such as free recall of words and perceptual sensitivity of word recognition and signal detection. The effects of caffeine on these latter parameters therefore seem to confirm our hypothesis that, at least when there is cholinergic dysfunction, caffeine acts as a cognition enhancer rather than a CNS stimulant.

In conclusion, our data indicate that caffeine has specific memory-enhancing properties and acts, at least partly, through cholinergic pathways. This raises the possibility that caffeine might be a protective factor against age-associated cognitive decline or even dementia. Another implication of our results is that many reports of the cholinergic effects of putative cognition enhancers, as assessed with the scopolamine model, should be read with caution. After all, we found that most of these effects could also be obtained by drinking three cups of coffee. We suggest therefore that caffeine should be used as a control drug in future scopolamine trials of putative cognition enhancers.

\section{References}

Bartus RT, Dean RL, Pontecorvo MJ, Flicker C (1985) The cholinergic hypothesis: A historical overview, current perspective, and future directions. Ann NY Acad Sci 444:332-358

Benowitz NL, Porchet H, Shiener L, Peyton JI (1988) Nicotine absorption and cardiovascular effects with smokeless tobacco use: comparison with eigarettes and nicotine gum. Clin. Pharmacol Ther 44:23-38

Bond A, Lader M (1974) The use of analogue scales in rating subjective feelings. Br J Med Psychol 80: 1-46

Briley $M$ (1990) Biochemical strategies in the search for cognition enhancers. Pharmacopsychiatry 2:75-80

Cacabelos R, Nordberg A, Caamano J, Franco-Maside A, Fernandez-Novoa L, Gomez MJ, Alvarez XA, Takeda M, Prous $J$, Nishimura T, Winblad B (1994) Molecular strategies for the 
first generations of antidementia drugs (1). Tacrine and related compounds. Drugs of Today 30:295-337

Fagan D, Swift CG, Tiplady B (1988) Effects of caffeine on vigilance and other performance tests in normal subjects. J Psychopharmacol 2:19-25

Gilman AG, Rall TW, Nies AS, Taylor P (1990) Goodman and Gilman's the pharmacological basis of therapeutics. Pergamon Press, New York, pp 150-166

Houx PJ (1991) Cognitive aging and health-related factors. Datawyse, Datawyse

Jarvis M (1993) Does caffeine intake enhance absolute levels of cognitive performance? Psychopharmacology 110:45-52

Jones GMM, Sahakian BJ, Warburton DM, Gray JA (1992) Effects of acute subcutaneous nicotine on attention, information processing and short-term memory in Alzheimer's disease. Psychopharmacology 108:485-494

Klatsky AL, Armstrong MA, Friedman GD (1993) Coffee, tea, and mortality. Ann Epidemiol 3:375-381

Levin ED (1992) Nicotinic systems and cognitive function. Psychopharmacology 108:417-431

Lieberman HR, Wurtman RJ, Emde GG, Roberts C, et al. (1987) The effects of low doses of caffeine on human performance and mood. Psychopharmacology 92:308-312

Loke WH (1988) Effects of caffeine on mood and memory. Physiol Behav $44: 367-372$

Molchan SE, Mellow AM, Lawlor BA, Weingartner HJ, Cohen RM, Cohen MR, Sunderland T (1990) TRH attenuates scopolamine-induced memory impairment in humans. Psychopharmacology 100:84-89

Molchan SE, Martinez RA, Hill JL, Weingartner HJ, Thompson $\mathrm{K}$, Vitiello B, Sunderland T (1992) Increased cognitive sensitivity to scopolamine with age and a perspective on the scopolamine model. Brain Res Rev 17:215-226

Nehlig A, Daval J-L, Debry G (1992) Caffeine and the central nervous system: mechanisms of action, biochemical, metabolic and psychostimulant effects. Brain Res Rev 17:139-170

Overall JE, Rhoades HM (1987) Adjusting p values for multiple tests of significance. In: Meltzer HY (ed) Psychopharmacology.
The third generation of progress. Raven Press, New York, pp 1013-1018

Pollack I, Norman DA (1964) A non-parametric analysis of recognition experiments. Psychon Sci 1:125-126

Preda L, Alberoni M, Bressi S, Cattaneo C et al. (1993) Effects of acute doses of oxiracetam in the scopolamine model of human amnesia. Psychopharmacology 110:421-426

Rusted J, Eaton-Williams P (1991) Distinguishing between attentional and amnestic effects in information processing: the separate and combined effects of scopolamine and nicotine on verbal free recall. Psychopharmacology 104:363-366

Rusted JM, Warburton DM (1988) The effects of scopolamine on working memory in healthy young volunteers. Psychopharmacology $96: 145-152$

Stavric B (1992) An update on research with coffee/caffeine (1989-1990). Food Chem Toxicol 30:533-555

Sternberg S (1969) Memory scanning:mental processes revealed by reaction time experiments. Am Sci 57:421-457

Surgeon General (1988) Nicotine addiction: the health consequences of smoking. A report of the Surgeon General. US Department of Health and Human Services, Rockville

Swift CG, Tiplady B (1988) The effects of age on the response to caffeine. Psychopharmacology 94:29-31

Terry WS, Phifer B (1986) Caffeine and memory performance on the AVLT. J Clin Psychol 42:860-863

Wesnes K, Parrott A (1992) Smoking, nicotine and human performance handbook of human performance. Academic Press, New York, pp 127-167

Wesnes K., Simpson P, Kidd A (1988) An investigation of the range of cognitive impairments induced by scopolamine $0.6 \mathrm{mg}$ s.c. Hum Psychopharmacol 3:27-41

Wesnes KA, Anand R, Simpson PM, Christmas L (1990) The use of a scopolamine model to study the potential nootropic effects of aniracetam and piracetam in healthy volunteers. I Psychopharmacol 4:219-232

Winer BJ (1971) Statistical principles in experimental design. McGraw-Hill, New York 